\title{
Cellular components involved in the cell death induced by cisplatin in the absence of $\mathbf{p 5 3}$ activation
}

\author{
IN HWA BAE, SUNG WOOK KANG, SUNG HWAN YOON and HONG-DUCK UM
}

Laboratory of Radiation Tumor Physiology, Korea Institute of Radiological \& Medical Sciences, Seoul, Korea

Received October 17, 2005; Accepted December 15, 2005

\begin{abstract}
Cisplatin (CDDP) is a DNA damaging agent and is widely used for treating cancer. While the role of p53 in CDDP-induced cell death has been stressed, evidence exists that CDDP can also kill p53-mutated cells. To investigate the latter mechanism, we performed a comparative study using three different human cell types, SNU-16 (a stomach cancer cell-line), U937 (a leukemic cell-line) and 293T (a kidney fibroblast cell-line), which are defective in terms of p53 activation. A focus was placed on $\mathrm{Bcl}-2$ family proteins, reactive oxygen species (ROS), and mitogen-activated protein kinases. Our results suggest that the ability of CDDP to kill these cells can be mediated by JNK, p38 MAPK and ROS, but not by ERK. It was also found that CDDP can increase the ratio of proapoptotic/pro-survival Bcl-2 members. While the importance of these components was found to depend on cell type, JNK was commonly involved in the deaths of all cell types examined. Therefore, the JNK pathway appears to be an ideal target for the modulation of the lethal action of CDDP in multiple types of p53-mutated cells.
\end{abstract}

\section{Introduction}

Cisplatin (cis-diammine-dichloro-platinum, CDDP) is a DNA damaging agent and is widely used for anticancer treatment. The major limitation of successful chemotherapy is the development of tumor cell resistance to this drug (1). To overcome this problem, it is essential that the cellular components involved in CDDP-induced cell death be identified. In particular, information regarding components that act in a broad spectrum of cell types would be useful for the development of more general therapeutic strategies.

P53 is a transcription factor that plays a key role in DNA damage check-point control $(2,3)$. In response to DNA damage caused by anticancer drugs or ionizing radiation, p53 is

Correspondence to: Dr Hong-Duck Um, Laboratory of Radiation Tumor Physiology, Korea Institute of Radiological and Medical Sciences, 215-4 Gongneung-dong, Nowon-gu, Seoul 139-706, Korea

E-mail: hdum@kcch.re.kr

Key words: cisplatin, cell death, JNK, ROS, Bcl-2, p53 stabilized and activated, and then coordinates DNA repair with cell cycle progression and apoptosis. The mechanism underlying the apoptotic action of p53 has been extensively characterized. Consequently, it has been well established that p53 can induce the expression of various types of pro-apoptotic proteins, such as Bax (4), Noxa (5) and Puma (6,7). It has also been reported that p53 can cause the down-regulation of the pro-survival protein, $\mathrm{Bcl}-2$ (8).

P53 also responds to CDDP and plays a crucial role in CDDP-induced cell death (9). This finding led some investigators to hypothesize that a loss of p53 function may contribute to the development of tumor cell resistance to CDDP. In fact, it was reported that p53 is mutated in $>50 \%$ of tumor cells (10-12). However, many of these tumors, despite the loss of p53 activation, remain responsive to CDDP. It has also been consistently demonstrated that disruption of p53 function does not make tumor cells resistant to $\operatorname{CDDP}(13,14)$. These observations suggest that CDDP can induce cell death in an alternative p53-independent manner. However, to date, cellular components involved in the p53-independent action of CDDP have not been systemically analyzed.

It has been reported that CDDP can influence the levels and activities of various types of cell death modulators, such as reactive oxygen species (ROS), mitogen-activated protein kinases (MAPKs) and Bcl-2 family proteins. For example, treating Jurkat leukemia cells with CDDP increased cellular ROS levels, and the prevention of this increase using antioxidants protected the cells against CDDP (15). Similar observations have been reported for testicular germ cell tumors (16), thus suggesting that ROS may act as mediators of CDDPinduced cell death. Major MAPK subfamily members include extracellular signal-regulated kinase (ERK), p38 kinase and c-Jun N-terminal kinase (JNK). It was reported that CDDP can kill HeLa cervical carcinoma cells by activating p38 MAPK and JNK (17). In addition, JNK was proposed to play a role in CDDP-induced cell death in A2780 ovarian cancer cells (18). The Bcl-2 family proteins include pro-apoptotic members such as Bax and Bak, in addition to pro-survival members such as Bcl-2 and $\mathrm{Bcl}-\mathrm{X}_{\mathrm{L}}$ (19). It was reported that treating OSC-4 oral carcinoma cells with CDDP caused increased levels of Bax and Bak and decreased Bcl-2 and Bcl- $X_{L}(20)$. These alterations may be critical for the lethal action of CDDP, given the view that cellular viability is determined by the balance between pro-apoptotic and pro-survival Bcl-2 family members (21). Despite the proposed roles of ROS, MAPKs and Bcl-2 family members in CDDP-induced cell death, the 
relationships between their actions and p53 function have not been clearly established.

In this study, we investigated whether ROS, MAPKs and Bcl-2 family proteins are involved in CDDP-induced cell death in the absence of p53 activation. In addition, to determine whether their actions are confined to a specific cell type, we performed a comparative study using three different human cell types, SNU-16 (a stomach cancer cell-line), U937 (leukemic cells) and 293T (kidney fibroblasts), which commonly show defective p53 activation. Our results suggest that CDDP can kill these cells via multiple cell type dependent mechanisms. Interestingly, unlike ERK, p38 MAPK, ROS and Bcl-2 family members, JNK was found to be commonly involved in the CDDP-induced death of all three cell types. Therefore, it appears that the JNK pathway could be a primary target for modulating the lethal action of CDDP in the absence of p53 activation.

\section{Materials and methods}

Antibodies. The antibodies raised against Bax, Bcl-2, ERK and p38 MAPK were purchased from Santa Cruz Biotechnology (Santa Cruz, CA). Antibodies against Bak and JNK were obtained from PharMingen/Transduction Laboratories (San Diego, CA). Antibodies specific to $\alpha$-tubulin and Bcl- $\mathrm{X}_{\mathrm{L}}$ were supplied by Calbiochem (La Jolla, CA). Anti-p53 was purchased from Dako (Glostrup, Denmark).

Cell culture and treatments. Cell culture medium and its supplements were supplied by BioWhittaker (Walkersville, MD). SNU-16, U937 and 293T cells were cultured in RPMI-1640 medium supplemented with $10 \%$ heat-inactivated fetal bovine serum and gentamicin $(50 \mu \mathrm{g} / \mathrm{ml})$. Human umbilical vein endothelial cells (HUVECs) were purchased from BioWhittaker, and maintained in EGM-2 medium supplemented with $20 \%$ heat-inactivated fetal bovine serum and endothelial cell growth factors $(30 \mu \mathrm{g} / \mathrm{ml})$. To treat the cells, U937 and SNU-16 cells were resuspended in a concentration of $1.5 \times 10^{5}$ cells $/ \mathrm{ml}$. HUVEC and 293T cells were replated in either 24-well plates ( $10^{5}$ cells/well $)$ or $100-\mathrm{mm}$ culture dishes $\left(2 \times 10^{6}\right.$ cells/dish). The cells were allowed to adhere overnight and then given the indicated treatments. Where specified, catalase and rotenone, inhibitors for MAPKs, were added at the indicated concentrations.

Analysis of cellular viability. The treated and untreated control cells were stained with propidium iodide $(5 \mu \mathrm{g} / \mathrm{ml})$ followed by flow cytometry analysis to monitor their staining intensity and size. The cells displaying both a normal size and a low permeability to propidium iodide were understood to be viable, as previously defined (22). All other populations were understood to be dead.

Analysis of cellular ROS levels. The cells were exposed to $50 \mu \mathrm{M}$ 2',7'-dichlorofluorescein diacetate (DCFH-DA; Molecular Probes, Eugene, OR) for $5 \mathrm{~min}$, and cell-associated levels of DCF fluorescence were analyzed by flow cytometry (23). Alternatively, fluorescence images were acquired and analyzed using a Leica TCS SP2 laser scanning confocal microscope (Leica Microsystems, Heidelberg).
Western blot analysis. Cells were lysed in Tris-HCl (40 mM, $\mathrm{pH} 8), 120 \mathrm{mM} \mathrm{NaCl}, 0.5 \%$ Nonidet P-40, and protease inhibitors $(2 \mu \mathrm{g} / \mathrm{ml}$ aprotinin, $2 \mu \mathrm{g} / \mathrm{ml}$ leupeptin and $100 \mu \mathrm{g} /$ $\mathrm{ml}$ PMSF). Equal amounts of the proteins were separated by SDS-PAGE and then electrotransferred to Immobilon membranes (Millipore, Bedford, MA), which were subsequently blotted using the indicated antibodies and visualized by chemiluminescence (ECL; Amersham Pharmacia, Uppsala, Sweden).

In vitro kinase assay. Cells were lysed in a buffer defined previously (24). The lysate proteins $(400 \mu \mathrm{g})$ were immunoprecipitated using antibodies against ERK, p38 MAPK or JNK and were resolved in $20 \mu \mathrm{l}$ of a kinase buffer containing $20 \mathrm{mM}$ Hepes ( $\mathrm{pH} 7.4$ ), $10 \mathrm{mM} \mathrm{MgCl}_{2}, 20 \mathrm{mM}$ ß-glycerophosphate, $10 \mathrm{mM} \mathrm{NaF}, 1 \mathrm{mM}$ DTT, $0.5 \mathrm{mM}$ sodium orthovanadate, $50 \mu \mathrm{M}$ ATP and $10 \mu \mathrm{Ci} \gamma-\left[{ }^{32} \mathrm{P}\right] \mathrm{ATP}$. The kinase reactions were initiated by adding $2 \mu \mathrm{g}$ of recombinant c-Jun protein (New England Biolabs, Beverly, MA) for JNK, and PHAS-1 (Stratagene, La Jolla, CA) for ERK and p38 MAPK. After 30-min incubation, the reactions were quenched by adding a boiled sample buffer, and the proteins were subsequently separated using $12 \%$ SDS-PAGE. A PhosphoImager using Tina 2.0 software was used to analyze the results.

\section{Results and discussion}

Cell death induced by CDDP in the absence of p53 activation. To identify the cellular components involved in CDDP-induced cell death in the absence of p53 activation, we used three different cell types, i.e. U937, SNU-16 and 293T cells. U937 cells have a p53 null mutation and, thus, do not express p53, which we confirmed by Western blotting (data not shown). SNU-16 cells also have a p53 mutation and p53 is inactivated in $293 \mathrm{~T}$ cells by the action of SV40 T antigen. Therefore, we expected that, in SNU-16 and 293T cells, p53 would not be stabilized or activated in response to DNA damage. To confirm this, these two cell types were treated with DNA damaging agents, i.e. $\gamma$-rays and CDDP. As expected, these treatments failed to increase p53 levels, as determined by Western blotting, for up to $8 \mathrm{~h}$ after treatment (Fig. 1A). In contrast, the same treatments efficiently elevated p53 levels in HUVECs (primary cultured normal endothelial cells), which was evident at only $30 \mathrm{~min}$ and $1 \mathrm{~h}$ after treating them with $\gamma$-rays or CDDP, respectively. Therefore, it was evident that p53 is either not expressed or inactivated in U937, SNU-16 and in 293T cells.

Despite their lack of a p53 response, U937, SNU-16 and 293 T cells succumbed to CDDP treatment (Fig. 1B). In the case of SNU-16 and U937 cells, $70-80 \%$ were killed by $50 \mu \mathrm{M}$ CDDP. Further elevation of the CDDP concentration to $250 \mu \mathrm{M}$ resulted in a marginal increase in cell death. In contrast, $50 \mu \mathrm{M}$ CDDP killed only $40 \%$ of $293 \mathrm{~T}$ cells and $250 \mu \mathrm{M}$ CDDP was required to kill 70-80\%. Considering these results, we used $50 \mu \mathrm{M}$ CDDP for SNU-16 and U937 cells and $250 \mu \mathrm{M}$ for $293 \mathrm{~T}$ in subsequent experiments.

Roles of Bcl-2 family members. It has been reported that CDDP can increase Bax/Bcl-2 ratios (20). Thus, to investigate whether this occurs in 293T, SNU-16 and U937 cells, we exposed them to lethal concentrations of CDDP. After various incubation 
(A)

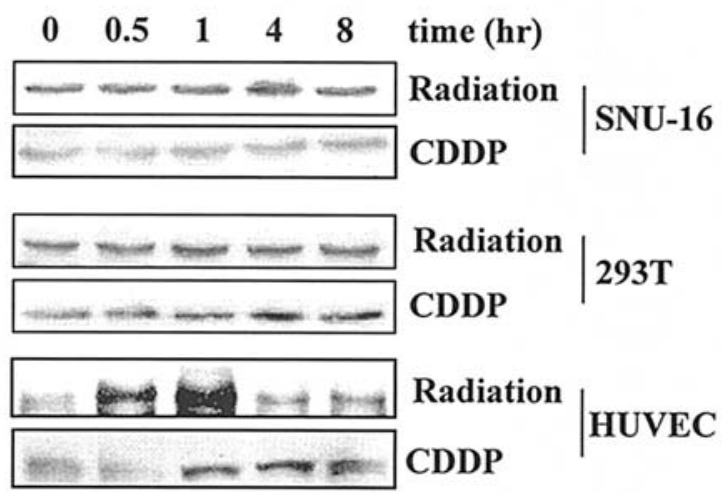

(B)

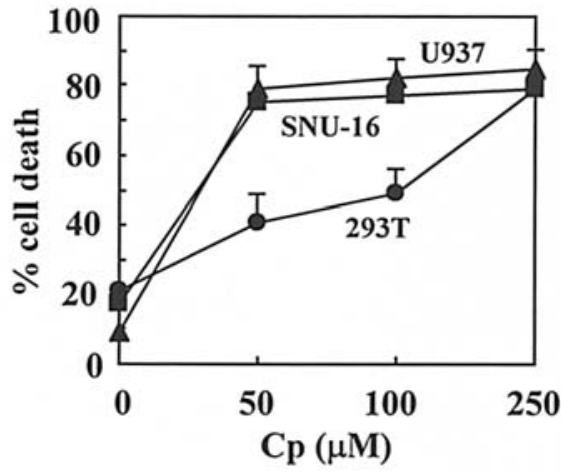

Figure 1. CDDP-induced cell death in the absence of p53 activation. (A), the indicated cell types were irradiated with $\gamma$-rays (5 Gy). To treat cells with CDDP, HUVECs and SNU-16 cells were exposed to CDDP $(50 \mu \mathrm{M})$, whereas CDDP at $250 \mu \mathrm{M}$ was used to treat $293 \mathrm{~T}$ cells. After the indicated incubation periods, cellular p53 levels were compared by Western blotting. (B), U937, SNU-16 or 293T cells were treated with the indicated concentrations of CDDP for 48 h, and cell viability was determined by flow cytometry. Values shown are the means of three separate experiments and error bars represent standard deviations.

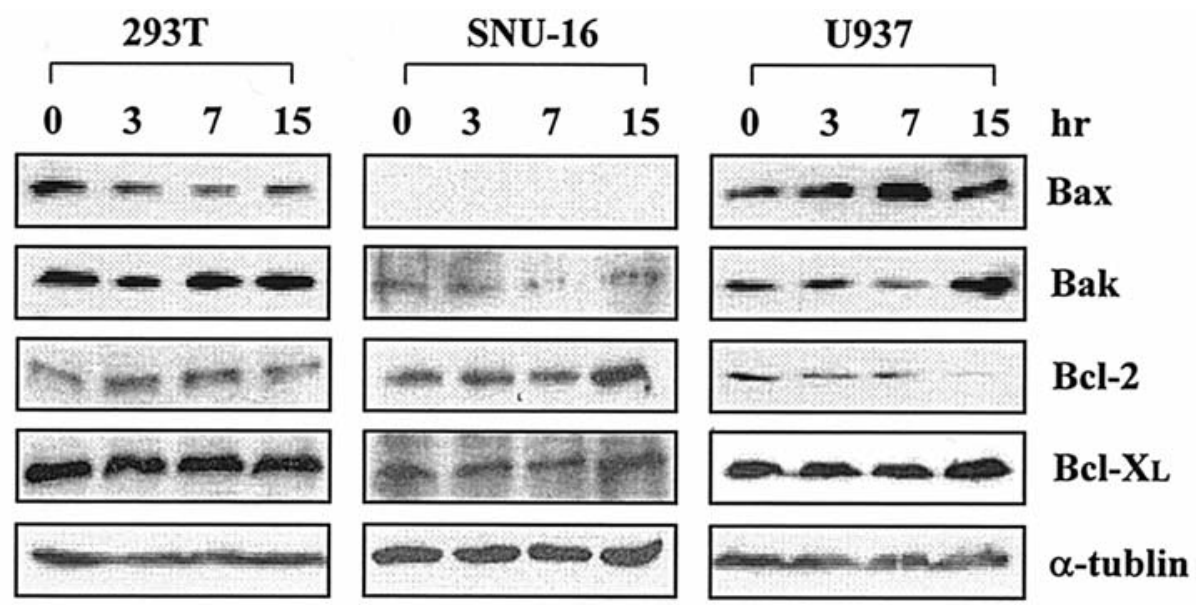

Figure 2. Effects of CDDP on the expressions of Bcl-2 family members. SNU-16 and U937, and 293T cells were treated with CDDP at 50 and $250 \mu$ M, respectively. After the indicated incubation periods, the cellular levels of Bax, Bak, Bcl-2 and Bcl- $\mathrm{X}_{\mathrm{L}}$ were compared by Western blotting using $\alpha$-tubulin as a loading control.

times, the cellular levels of pro-apoptotic (Bax and Bak) and pro-survival (Bcl-2 and Bcl- $\mathrm{X}_{\mathrm{L}}$ ) members were compared by Western blotting. In $293 \mathrm{~T}$ and SNU-16 cells, CDDP did not significantly up-regulate Bax and Bak nor down-regulate

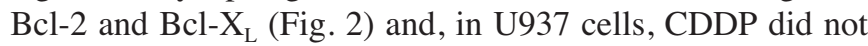
significantly influence Bcl- $\mathrm{X}_{\mathrm{L}}$ levels. However, CDDP did elevate Bax and Bak levels in U937 cells at 7 and $15 \mathrm{~h}$, respectively, after its treatment. Moreover, CDDP reduced Bcl-2 levels in U937 cells, which was optimally observed at $15 \mathrm{~h}$. CDDP consistently increased levels of Bcl-2 ubiquitination, as analyzed by Western blotting at $15 \mathrm{~h}$ (data not shown), which suggests that CDDP reduces Bcl-2 levels in U937 cells by promoting its degradation. These results suggest that CDDP increases the ratio of pro-apoptotic to pro-survival Bcl-2 family proteins in U937 cells, but not in the other cell types tested. Although it has been reported that p53 can up-regulate and down-regulate levels of Bax and Bcl-2 respectively $(4,8)$, our data suggest that CDDP can do this in a p53-independent manner.
Role of ROS. To investigate whether lethal concentrations of CDDP increase cellular ROS levels, CDDP-treated and untreated control cells were stained with DCF, and cellassociated levels of DCF fluorescence were compared by flow cytometry. CDDP treatment elevated DCF fluorescence in $293 \mathrm{~T}$ cells (Fig. 3A), and this effect peaked after $5 \mathrm{~h}$. Similar results were obtained when DCF fluorescence was analyzed by confocal microscopy (Fig. 3B). These observations suggest that CDDP increases ROS levels in $293 \mathrm{~T}$ cells. The increase in DCF fluorescence was prevented when $293 \mathrm{~T}$ cells were co-treated with rotenone $(0.1 \mu \mathrm{M})$, an inhibitor of the mitochondrial respiratory chain (mean values of DCF fluorescence by flow cytometry were as follows; untreated, 4.45; rotenone-treated, 3.27; CDDP-treated, 12.26; CDDP and rotenone-treated, 5.21). Therefore, CDDP appears to promote mitochondrial ROS production in 293T cells, as has been proposed in Jurkat T cells (15). In contrast, CDDP failed to increase DCF fluorescence in U937 and in SNU-16 cells. This was confirmed by flow cytometry (Fig. 3A) or confocal 
(A)

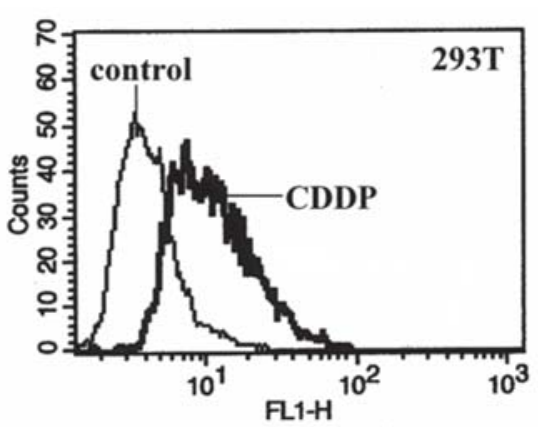

(B)

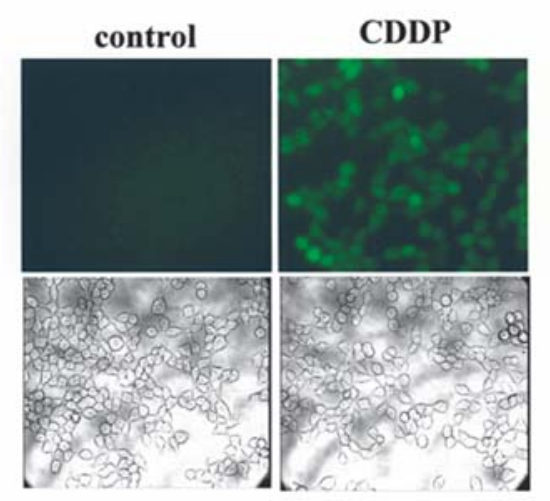

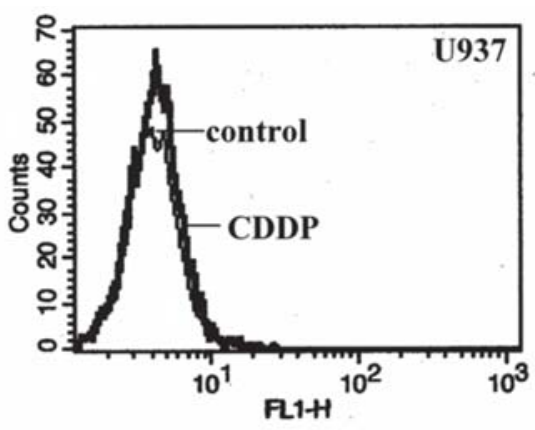

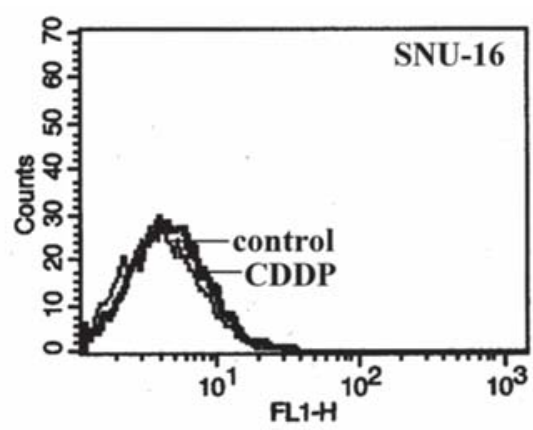

(C)

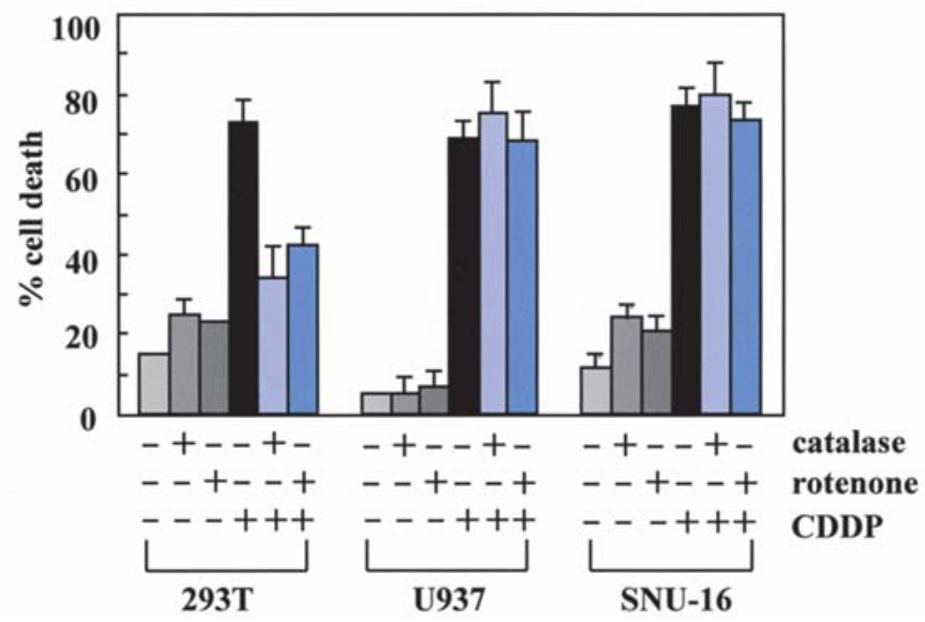

Figure 3. Role of ROS in p53-independent cell death induced by CDDP. (A), cells were exposed to CDDP (SNU-16 and U937 at $50 \mu \mathrm{M}$; $293 \mathrm{~T}$ at $250 \mu \mathrm{M}$ ) for $5 \mathrm{~h}$. Treated and untreated control cells were stained with DCF, and analyzed by flow cytometry. (B), DCF fluorescence from $293 \mathrm{~T}$ cells was analyzed by confocal microscopy (x20) (top two panels). Cells were also visualized by light microscopy (bottom two panels). (C), CDDP treatment was performed in the presence or absence of catalase $(1,500 \mathrm{U} / \mathrm{ml})$ or rotenone $(0.1 \mu \mathrm{M})$. Cellular viabilities were analyzed $48 \mathrm{~h}$ after treatment.

microscopy (data not shown) assays, which were followed from $5 \mathrm{~min}$ to $24 \mathrm{~h}$ after treatment. Consistent with these results, the CDDP-induced death of 293T cells, but not of SNU-16 or U937, was attenuated when cells were co-treated with rotenone or catalase, a $\mathrm{H}_{2} \mathrm{O}_{2}$-degrading enzyme (Fig. 3C). Therefore, ROS appear to mediate the lethal action of CDDP in $293 \mathrm{~T}$ cells, but not in U937 and SNU-16 cells.

Roles of MAPKs. The role of ERK in CDDP-induced cell death remains controversial. For example, though it was proposed that ERK mediates the lethal action of CDDP in HeLa cells (25), others reported that CDDP failed to activate ERK in these cells (17). To determine the role of ERK in the present systems, its activity was analyzed by using in vitro kinase assays at various times after CDDP treatment. It was found that CDDP activated ERK in 293T and U937 cells but not in SNU-16 cells (Fig. 4A). However, PD 98059, an ERK inhibitor, failed to rescue any of these cell types from CDDP-induced cell death (Fig. 4B). Therefore, it appears that CDDP-induced cell death is not always accompanied by ERK activation, and that ERK, though activated, does not support the lethal action of CDDP.

In contrast to ERK, CDDP activated p38 MAPK and JNK in all three cell lines (Fig. 4A). However, SB 203580, an inhibitor of $\mathrm{p} 38$ MAPK, suppressed the lethal action of CDDP only in U937 cells and not in 293T and SNU-16 (Fig. 4B), suggesting that p38 MAPK mediates the CDDP-induced death of U937 cells, but not that of the other two cell-lines. Therefore, the role of p38 MAPK in CDDP-induced death appears to depend on cell type. In contrast, the lethality by CDDP was reduced in all three cell types when they were co-treated with SP 600125, an inhibitor for JNK, suggesting that JNK acts as a common mediator of CDDP-induced cell death.

This study shows that CDDP can kill p53-deficient/mutated cells via multiple mechanisms, which are summarized in Table I. Our data suggests that the lethal action of CDDP can be mediated by JNK, p38 MAPK or ROS, and that CDDPinduced cell death can be accompanied by an increase in proapoptotic and a decrease in pro-survival members of the Bcl-2 family. Furthermore, our data support the view that ERK does not participate in CDDP-induced cell death. The importance of these participations appears to be dependent on cell type. For example, while ROS and p38 MAPK were involved in the death of $293 \mathrm{~T}$ and U937 cells, respectively, CDDP increased the ratio of pro-apoptotic/pro-survival Bcl-2 proteins in U937 cells only. Therefore, it appears that ROS, p38 MAPK and Bcl-2 family proteins may independently support CDDP-induced cell death. In contrast, JNK was found to mediate the lethality of CDDP in all cell types. The role of 
(A)

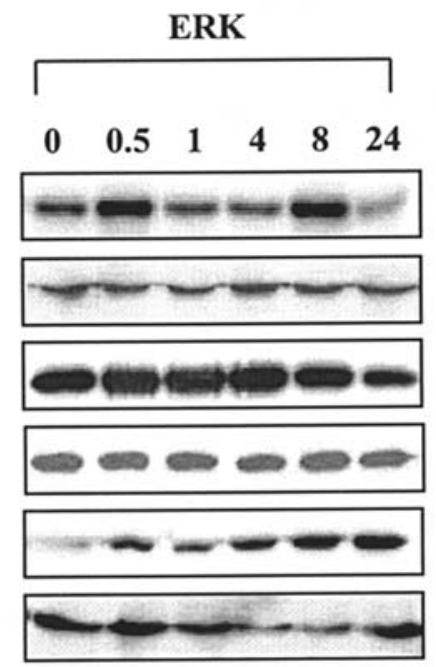

P38 MAPK

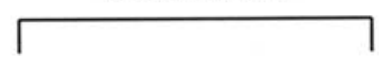

$\begin{array}{llllll}0 & 0.5 & 1 & 4 & 8 & 24\end{array}$
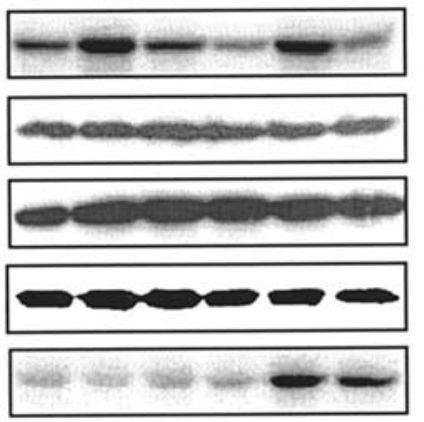

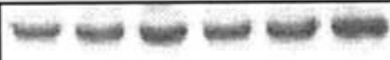

JNK
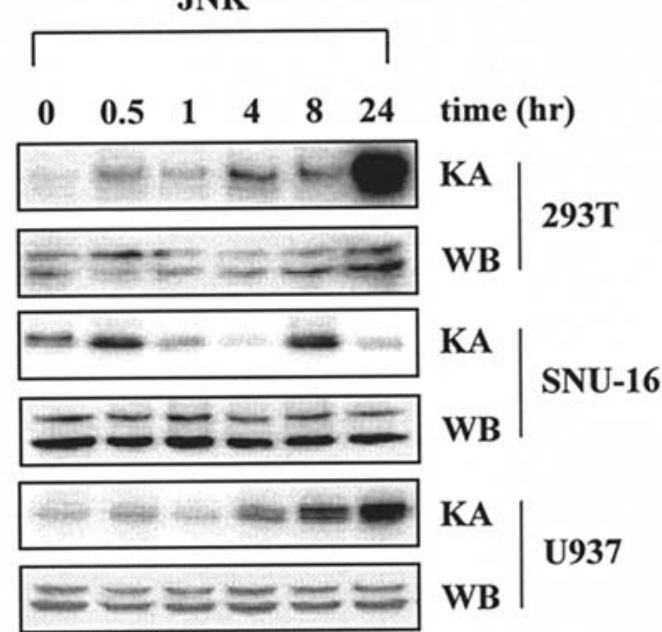

(B)

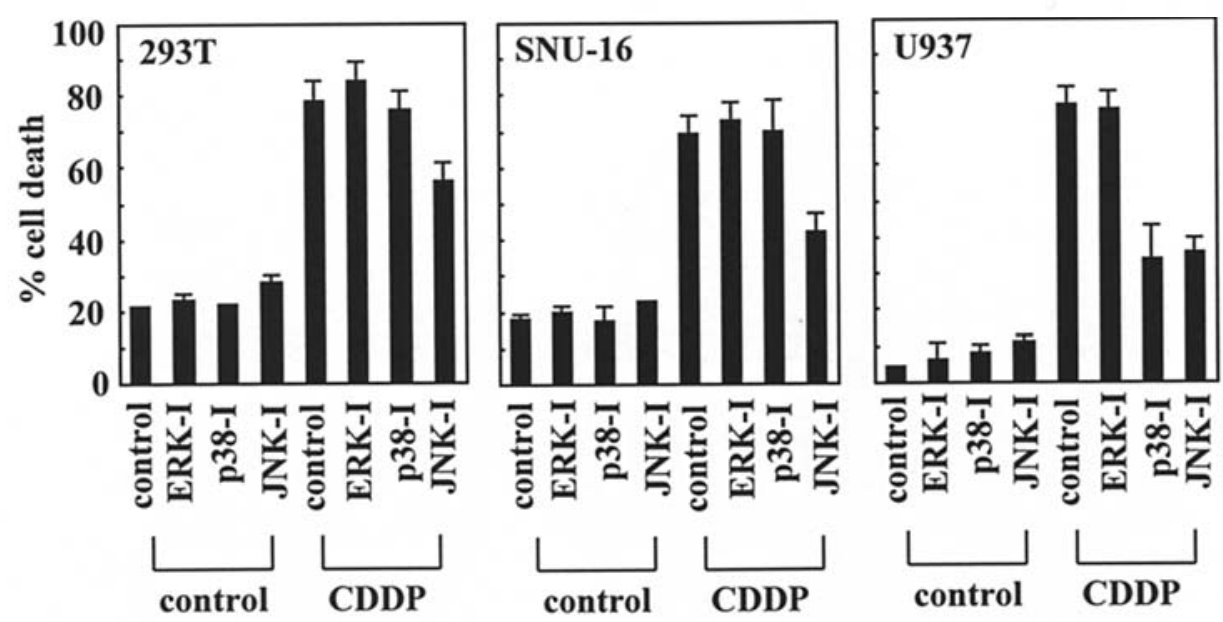

Figure 4. Role of MAPKs in p53-independent CDDP-induced cell death. (A), cells were treated with CDDP (SNU-16 and U937 at $50 \mu \mathrm{M} ; 293 \mathrm{~T}$ at $250 \mu \mathrm{M}$ ). After the indicated periods, ERK, p38 MAPK and JNK activity was analyzed by using in vitro kinase assays. The substrates used were recombinant c-Jun protein for JNK or PHAS-1 for ERK and p38 MAPK. The protein levels of these MAPKs were also probed using specific antibodies. In the case of JNK, two isoforms (p54 and p46) were detected. (B), the three cell-lines were also treated with CDDP in the presence or absence of PD 98059, SB 203580 or SP 600125 , which inhibit ERK, p38 MAPK and JNK, respectively. All of these inhibitors were used at $10 \mu \mathrm{M}$.

Table I. Cellular components involved in CDDP-induced cell death in the absence of p53 activation.

\begin{tabular}{lccccc}
\hline Cell type & JNK & p38 MAPK & ERK & ROS & Ratio of (Bax+Bak)/Bcl-2 \\
\hline 293T & o & x & x & o & x \\
SNU-16 & o & x & x & x & x \\
U937 & o & o & x & x & 0 \\
\hline
\end{tabular}

Involved and non-involved components are indicated by o and x, respectively.

JNK in CDDP-induced cell death has also been proposed for other cells, e.g., cervical (17) and ovarian cancer cells (18). Therefore, the ability of JNK to mediate CDDP-induced cell death appears to be a feature of many cell types, which suggests that the JNK pathway represents a primary target for the modulation of CDDP lethality in p53-deficient/mutated cells.

\section{Acknowledgements}

This study was supported by Korea Science and Engineering Foundation (KOSEF) and Ministry of Science and Technology (MOST), Korean government, through its National Nuclear Technology Program and in part by the Molecular and Cellular BioDiscovery Research Program. 


\section{References}

1. Kartalou M and Essigmann JM: Recognition of cisplatin adducts by cellular proteins. Mutat Res 478: 1-21, 2001.

2. Fei P and El-Deiry WS: P53 and radiation responses. Oncogene 22: 5774-5783, 2003.

3. Iliakis $\mathrm{G}$, Wang $\mathrm{Y}$, Guan $\mathrm{J}$ and Wang H: DNA damage checkpoint control in cells exposed to ionizing radiation. Oncogene 22: $5834-5847,2003$

4. Miyashita T and Reed JC: Tumor suppressor p53 is a direct transcriptional activator of the human bax gene. Cell 80: 293-299, 1995.

5. Oda E, Ohki R, Murasawa H, Nemoto J, Shibue T, Yamashita T, Tokino T, Taniguchi T and Tanaka N: Noxa, a BH3-only member of the Bcl-2 family and candidate mediator of p53-induced apoptosis. Science 288: 1053-1058, 2000.

6. Yu J, Zhang L, Hwang PM, Kinzler KW and Vogelstein B: Puma induces the rapid apoptosis of colorectal cancer cells. Mol Cell 7: 673-682, 2001.

7. Nakano K and Vousden KH: Puma, a novel proapoptotic gene, is induced by p53. Mol Cell 7: 683-694, 2001.

8. Harn HJ, Ho LI, Liu GC, Lin FG, Lin JJ, Chang JY and Lee WH: Down-regulation of bcl-2 by p53 in nasopharyngeal carcinoma and lack of detection of its specific $\mathrm{t}(14 ; 18)$ chromosomal translocation in fixed tissues. Histopathology 28: 317-323, 1996.

9. Siddik Z: Cisplatin: mode of cytotoxic action and molecular basis of resistance. Oncogene 22: 7265-7279, 2003.

10. Culotta E and Koshland DE Jr: P53 sweeps through cancer research. Science 262: 1958-1961, 1993.

11. Soussi T and Lozano G: P53 mutation heterogeneity in cancer. Biochem Biophys Res Commun 331: 834-842, 2005.

12. Soussi T and Beroud C: Assessing TP53 status in human tumours to evaluate clinical outcome. Nat Rev Cancer 1: 233-240, 2001.

13. Fan S, Smith ML, Rivet DJ, Duba D, Zhan Q, Kohn KW, Fornace AJ Jr and O'Connor PM: Disruption of p53 function sensitizes breast cancer MCF-7 cells to cisplatin and pentoxifylline. Cancer Res 55: 1649-1654, 1995.

14. Hawkins DS, Demers GW and Galloway DA: Inactivation of p53 enhances sensitivity to multiple chemotherapeutic agents. Cancer Res 56: 892-898, 1996.
15. Huang HL, Fang LW, Lu SP, Chou CK, Luh TY and Lai MZ: DNA-damaging agents induce apoptosis through reactive oxygen species-dependent Fas aggregation. Oncogene 22: 8168-8177, 2003

16. Schweyer S, Soruri A, Heintze A, Radzun HJ and Fayyazi A: The role of reactive oxygen species in cisplatin-induced apoptosis in human malignant testicular germ cell lines. Int J Oncol 25: 1671-1676, 2004.

17. Brozovic A, Fritz G, Christmann M, Zisowsky J, Jaehde U, Osmak M and Kaina B: Long-term activation of SAPK/JNK, p38 kinase and Fas-L expression by cisplatin is attenuated in human carcinoma cells that acquired drug resistance. Int J Cancer 112: 974-985, 2004

18. Li F, Meng L, Zhou J, Xing H, Wang S, Xu G, Zhu H, Wang B, Chen G, Lu YP and Ma D: Reversing chemoresistance in cisplatin-resistant human ovarian cancer cells: a role of c-Jun $\mathrm{NH}_{2}$-terminal kinase 1. Biochem Biophys Res Commun 335: 1070-1077, 2005.

19. Bouillet P and Strasser A: BH3-only proteins - evolutionally conserved pro-apoptotic Bcl-2 family members essential for initiating programmed cell death. J Cell Sci 115: 1567-1574, 2002.

20. Li D, Ueta E, Kimura T, Yamamoto T and Osaki T: Reactive oxygen species (ROS) control the expression of Bcl-2 family proteins by regulating their phosphorylation and ubiquitination. Cancer Sci 95: 644-650, 2004.

21. Adams JM and Cory S: Life-or-death decisions by the Bcl-2 protein family. Trends Biochem Sci 26: 61-66, 2001.

22. Mangan DF, Welch GR and Wahl SM: Lipopolysaccharide, tumor necrosis factor-alpha and IL-1 beta prevent programmed cell death (apoptosis) in human peripheral blood monocytes. J Immunol 146: 1541-1546, 1991

23. Bass DA, Parce JW, Dechatelet LR, Szejda P, Seeds MC and Thomas M: Flow cytometric studies of oxidative product formation by neutrophils: a graded response to membrane stimulation. J Immunol 130: 1910-1917, 1983.

24. Kim DK, Cho ES, Seong JK and Um HD: Adaptive concentrations of hydrogen peroxide suppress cell death by blocking the activation of SAPK/JNK pathway. J Cell Sci 114: 4329-4334, 2001.

25. Wang X, Martindale JL and Holbrook NJ: Requirement for ERK activation in cisplatin-induced apoptosis. J Biol Chem 275: 39435-39443, 2000. 